вещества лучистой зоны, в результате чего на расстоянии около 0,3 радиуса Солнца от его поверхности возникают условия для возбуджения конвективного переноса энергии. Выше этой границы лежит слой, который называют конвективной зоной. Существование и локализация конвективной зоны Солнца определяется двумя причинами: первая - структурный (лучистый) градиент температуры увеличивается из-за роста непрозрачности при падении температуры; вторая - адиабатический градиент температуры вспльвающих элементов уменьшает свою величину в зонах частичной ионизации водорода и гелия.

Именно конвективная зона играет роль полигона, где зарождаются основные процессы, ответственные за циклические проявления активности Солнца. Вместе с тем, часть конвективного потока энергии, которая идёт из недр Солнца, накапливается и переносится наружу в "магнитной форме". Специфичность магнитного переноса энергии проявляется в циклических изменениях большинства порождаемых магнитными полями явлений, которые принято называть магнитной активностью Солнца. Основным механизмом, который обеспечивает циклический характер колебаний магнитной активности, служит турбулентное динамо, локализованное в конвективной зоне.

Наиболее благоприятным местом для генерации тороидального магнитного поля, от величины которого зависит интенсивность пятнообразования, служат глубокие слои вблизи дна конвективной зоны, охватывающие слой проникающей конвекции (конвективный овершут) и тахоклин. В овершуте возникают необходимые условия для формирования слоя длительного удержания магнитных полей, тогда как в тахоклине вследствие резкого падения угловой скорости в присутствии слабого полоидального поля эффективно генерируется сильное тороидальное поле. Паркеровская плавучесть этого поля со временем доминирует над эффектами антиплавучести. Поэтому в конечном итоге тороидальное поле поднимается к поверхности и формирует тем самым магнитные биполярные группы солнечных пятен. Важным фактором физических процессов в глубинных слоях является также направленное к экватору меридиональное течение, которое в рамках модели гидромагнитного динамо обеспечивает миграцию тороидальных полей от высоких гелиоширот к низким. Отмечены последние исследования автора о роли глубинных слоёв солнечной конвективной зоны в объяснении наблюдаемых явлений двойных максимумов цикла солнечных пятен.

Ключевые слова: Солнце, термоядерный синтез, излучение, конвекция, магнитная энергия, солнечная активность, овершут, тахоклин, магнитная плавучесть, меридиональная циркуляция, турбулентное динамо, магнитный цикл.

V. Krivodubskij, Dr. Sci.

Astronomical Observatory of Taras Schevchenko National University of Kyiv, Kyiv

\title{
THE ROLE OF THE CONVECTIVE ZONE IN THE EXCITATION OF THE MAGNETIC ACTIVITY OF THE SUN
}

The sources of energy of solar activity are analyzed. The primary source of solar energy is the core of the Sun, where as a result of the reactions of thermonuclear fusion, energy is released in the form of $y$-quanta and neutrino particles that propagate outward. At approaching the surface, the temperature is rapidly decreasing and at the same time the opacity of the substance of the radiation zone steadily increases, resulting in the creation of conditions for the emergence of a convective energy transfer at a distance from surface of about 0.3 radius of the Sun. Above this boundary lies a layer called the convection zone. The existence and localization of the convection zone of the Sun is determined by two reasons: the first - the structural (radiative) temperature gradient increases due to increased opacity when the temperature drops; the second - the adiabatic gradient of the temperature of the floating elements reduces its value in the zones of partial ionization of hydrogen and helium.

It is the convection zone that plays the role of the landfill, where the main processes are born, which are responsible for the cyclic manifestations of the Sun's activity. However, part of the convective flow of energy coming from the interior of the Sun, accumulates and is carried upwards in the "magnetic form". An important specific property of magnetic energy transfer is manifested in cyclic changes in most of the phenomena generated by magnetic fields, which are called magnetic activity of the Sun. The main mechanism providing the cyclic nature of the fluctuations of magnetic activity is the turbulent dynamo, localized in the convection zone.

The most favorable place for the generation of a toroidal magnetic field, on which the intensity of spot formation depends, are the deep layers near the bottom of the convection zone, covering the layer of permeable convection (convective overshoot layer) and the tachocline. Overshoot creates the necessary conditions for the formation of a layer of long retention maintenance of magnetic fields, whereas in the tachocline, due to the sharp decrease in angular velocity in the presence of a weak poloidal field, a powerful toroidal field is effectively generated. Parker buoyancy of this field dominates over the effects of anti-buoyancy. Therefore, eventually, toroidal field rises to the surface and forms magnetic bipolar groups of sunspots. An important factor of physical processes in the deep layers is also the meridional flow directed to the equator, which, within the framework of the hydromagnetic dynamo model, provides the migration of toroidal fields from high latitudes to low ones. The author's recent studies on the role of the deep layers of the solar convection zone in explaining the observed phenomenon of double peaks of the cycle of sunspots are noted.

Keywords: Sun; excitation of solar energy; radiation; convection; magnetic energy; convective zone; solar activity; overshoot layer; tachocline; magnetic buoyancy; meridional circulation; turbulent dynamo; magnetic cycle.

\section{УдК 524.7}

\section{КОМПАКТНІ ГАЛАКТИКИ З АКТИВНИМ ЗОРЕУТВОРЕННЯМ: ТЕПЛОВЕ ВИПРОМІНЮВАННЯ У РАДІОКОНТИНУУМІ НА ЧАСТОТІ 1.4 ГГЦ}

Визначено частку теплового компонента в загальному випромінюванні в радіоконтинуумі на частоті 1.4 ГГи від 193 компактних галактик з активним зореутворенням. Розподіл цієї величини є близьким до лог-нормального з медіаною між $6 \%$ та $14 \%$. Частка зростає за збільшення $E W\left(H_{\beta}\right)$ еквівалентної ширини емісійної лінії $H_{\beta}$ при постійному індексу кольору $g-r$, або збільшенні індексу кольору $g-r$ при постійній $E W\left(H_{\beta}\right)$, еквівалентній ширині емісійної лінії $H_{\beta}$. Знайдено залежність від обох параметрів одночасно. При збільшенні віку спалаху зореутворення частка теплового випромінювання зменшується. Не виявлено статистично значущої залежності від вмісту важких елементів.

Ключові слова: галактики з активним зореутворенням, випромінювання в радіоконтинуумі, теплове випромінювання.

Вступ. Зореутворення $є$ одним із найважливіших процесів у галактиці, що впливає на її еволюцію та визначає хімічний склад. Зважаючи на це, дослідженню галактик, у яких цей процес перебігає активно, присвячено багато праць. Проведено значну кількість досліджень випромінювання галактик з активним зореутворенням у різних діапазонах (від ультрафріолетового до радіо), які $є$ індикаторами цього процесу; проаналізовано історію зореутворення та визначено характеристики, параметри й особливості цього процесу у галактик різних типів та на різних червоних зміщеннях (див., напр., огляд [6], роботи [1, 9, 12-15, 18-20, 22-26, 28, 30, 32-34, 36-37, 40-41, 43-44, 48].

Одним з індикаторів процесу зореутворення в галактиках $€$ випромінювання в радіоконтинуумі на частоті 1.4 ГГц. Випромінювання в радіоконтинуумі на частотах, менших від кількох гігагерц, зазвичай має нетеплове походження, 
хоча в зонах HII іонізованого водню тепловий компонент (free-free випромінювання) може бути помітним. Нетепловий компонент у галактиках без активних галактичних ядер є наслідком синхротронного випромінювання електронів м'яких космічних променів, захоплених магнітним полем галактики. Ударні хвилі, пов'язані із залишками спалахів наднових зір типів SN II та SN lb, розглядаються як основні джерела електронів м'яких космічних променів у галактиках без активних ядер (див. огляд $[8,11])$. Оскільки наднові SN II та SN Ib утворюються завдяки еволюції масивних зір із масами $\mathrm{M} \sim 8 \mathrm{M} \odot$, час життя яких менше $3 \times 10^{7}$ років, то в певному сенсі нетеплове випромінювання у радіоконтинуумі на 1.4 ГГц також є пов'язаним із процесами зореутворення, хоч і на більшій шкалі часу порівняно $з$ тепловим (free-free випромінюванням) у радіоконтинуумі в зонах HII.

Дослідженню випромінювання галактик різних типів у радіоконтинуумі на частоті 1.4 ГГц та його кореляції з випромінюванням в інфрачервоному й оптичному діапазонах присвячено роботи [4-5, 10-11, 21, 27, 35, 38, 45, 48].

У роботах $[35,38]$ проаналізовано властивості випромінювання у радіоконтинуумі на 1.4 ГГц 52 галактик з активним зореутворенням з вибірки LCGs, яким є притаманними високі світність та еквівалентна ширина $E W\left(H_{\beta}\right)$ емісійної лінії $H_{\beta}$, що свідчать про молодість спалаху зореутворення. Також було оцінено швидкість зореутворення та показано, що, незважаючи на високу активність зореутворення, випромінювання в радіоконтинуумі на 1.4 ГГц є переважно нетепловим, а частка теплового компонента у загальному випромінюванні в радіоконтинуумі становить у середньому $17 \%$.

Метою виконаної роботи є визначення частки теплового компонента (free-free випромінювання) в загальному випромінюванні у радіоконтинуумі на частоті 1.4 ГГц у компактних галактиках з активним зореутворенням 3 нової вибірки (це зроблено таким чином, як й у роботах [35, 38] для LCGs-вибірки).

Вибірка галактик. Дані спостережень у радіоконтинуумі на 1.4 ГГи. Для дослідження теплового випромінювання в радіоконтинуумі на частоті 1.4 ГГц було використано вибірку галактик CSFG [43] , яка охоплює близько 14000 компактних галактик з активним зореутворенням, що має характер спалаху. Вибірку було створено на основі спектрального огляду неба SDSS Data Release 12 (SDSS DR12) [46], який містить дві підвибірки: із класичного SDSS огляду з Data Release 9 та більш ранніх, а також BOSS з Data Release 10 та 12. Спектри з підвибірок, що базуються на класичному SDSS та BOSS, отримано в різних діапазонах, $\sim 3800-9200 \AA$ і $\sim 3600-10000 \AA$, та з різними апертурами, 3 arcsec та 2 arcsec, відповідно.

До складу базової вибірки CSFG [43] увійшли об'єкти, які задовольняють критеріям: наявність у спектрі емісійних ліній $H_{\beta}$ з еквівалентною шириною $E W\left(H_{\beta}\right) \geq 10 \AA$; компактність; наявність надійно зареєстрованої лінії [O III] $\lambda 4363 \AA$ (похибка у визначенні потоку у лінії < 50 \% величини), яка надає можливість надійного визначення вмісту важких елементів, та відсутність таких спектральних ознак наявності активних галактичних ядер як широкі емісійні лінії у спектрах галактик Sy1 та ліній високої іонізації [NeV]入3485 А̊ і Hell $\lambda 4686 \AA$ у спектрах Sy2. На діаграмі [OIII] $\lambda 5007 \AA / H_{\beta} \lambda 4861 \AA$ - [NII] $65583 / H_{\alpha} \lambda 6563 \AA$ [2] галактики CSFG вибірки займають позиції, притаманні галактикам з активним зореутворенням, а не з активними галактичними ядрами.

Галактики CSFG вибірки мають червоні зміщення в діапазоні z $=0-1$, значення медіани розподілу 0.2. Для всієї вибірки медіанне значення еквівалентної ширини $E W\left(H_{\beta}\right) \approx 40 \AA$, у той час як значна частина галактик ( $\left.10 \%\right)$ має еквівалентну ширину $E W\left(H_{\beta}\right)>100 \AA \AA$, що свідчить про наявність молодого спалаху зореутворення. Зазначимо, що у спектрах галактик вибірки рекомбінаційну лінію $H_{\alpha}$ видно у спектрах галактик з $z<0.4$ у випадку підвибірки із класичної SDSS, та з z 0.52 у випадку BOSS галактик.

Спектральні дані CSFG вибірки було доповнено даними про випромінювання галактик у радіоконтинуумі на частоті 1.4 ГГц за даними оглядів FIRST та NVSS.

Для вибірки CSFG галактик за даними огляду неба FIRST, розміщеними на сайті http://sundog.stsci.edu/first/catalogs.html/, було проведено пошук джерел випромінювання в радіоконтинуумі із граничною кутовою відстанню $\leq 15 "$.

FIRST (Faint Images of the Radio Sky at Twenty Centimeters) [3] - це Very Large Array (VLA) огляд неба в радіоконтинуумі на довжині хвилі 20 см (1.4 ГГц) із шириною діаграми направленості 5" та 1 б чутливості 0.15 мЯн. Ділянки неба, на яких виконано огляди FIRST та SDSS, досить близькі. Версія каталогу огляду FIRST на дату 17 грудня 2014 р. (анонсована як фінальна) містить дані спостережень 946432 радіоджерела на площі неба понад 10575 квадратних градусів. 3 порогом чутливості 1 мЯн спостерігається 90 джерел випромінювання на ділянці неба 1 квадратний градус. Однак тут слід зауважити, що FIRST, як й інші огляди, що виконані з радіоінтерферометром, має певні обмеження із чутливості. Точність визначення положення джерела радіовипромінювання змінюється від 0.5" (зареєстрований потік 3 мЯн) до 1" для слабших джерел. Оцінено, що $\sim 40 \%$ радіоджерел із каталогу FIRST мають оптичних партнерів в SDSS. Tак, у роботі [29] після ототожнення джерел із каталогу FIRST із даними огляду SDSS було отримано, що 35 \% радіоджерел мають оптичного партнера з SDSS на відстані 3", 61 \% - на відстані $10 ", 98$ \% - $30 "$.

Огляд NVSS (NRAO-VLA Sky Survey) [47] також $€$ VLA оглядом неба в радіоконтинуумі на частоті 1.4 ГГц, але виконаний з іншою конфігурацією антени, ніж у FIRST, та з меншою роздільною здатністю - 45". Менша роздільна здатність огляду приводить до того, що у ньому з більшою точністю вимірюється потік протяжних радіоджерел, тоді як огляди з більшою роздільною здатність можуть втрачати значну частину потоку таких джерел. Точність визначення положень коливається від 1" для найбільш яскравих джерел до 7" у найслабших. Огляд NVSS містить понад 1,8 млн унікальних спостережень радіоджерел, яскравіших від $2.5 \mathrm{~m}$ н, у ділянці неба на північ від $\delta=-40^{\circ}$. Для вибірки CSFG галактик було проведено пошук джерел радіовипромінювання в огляді NVSS також із граничною кутовою відстанню $\leq 15 "$.

Внаслідок ототожнення було знайдено 618 радіоджерел із каталогу NVSS, що перебувають на відстані менш ніж 15" від об'єктів вибірки, 643 подібних радіоджерел у каталозі FIRST. Для 973 об'єктів вибірки були знайдені потенційні ототожнення, якщо враховувати водночас дані обох каталогів. В останньому випадку це переважно були ті ж 
самі радіоджерела, але інколи для одного об'єкта з вибірки знаходили різні близькі радіоджерела в різних каталогах. Для 97 галактик вибірки одночасно є дані випромінювання в радіоконтинуумі на 1.4 ГГц з бази даних FIRST та NVSS. Співвідношення між ними приведено на рис. 1. 3 потенційних ототожнень для подальшої візуальної перевірки ми вибрали 221 об'єкт, що був умовно класифікований як компактна карликова галактика з активним зореутворенням. Під час візуального контролю з оглядовими картами SDSS було вилучено сумнівні позиційні ототожнення CSFG галактик із радіоджерелами, а також ураховано ймовірність того, що радіоджерело потрапляє у боковий пелюсток мережі радіотелескопів (інколи вона була великою). Для остаточно відібраних 193 галактик із відомими потоками випромінювання $F_{H \beta}$ та $F_{1.4 G \mathrm{z}}$ кутова відстань між оптичними та радіоджерелами становить $\leq 2.5 "$. У фінальний список потрапила тільки одна галактика з DR12 SDSS, яка знаходиться не дуже далеко (z=0.0373). Загалом галактики вибірки, ототожнені з радіоджерелами, лежать у діапазоні червоних зміщень z $=0.0044 \ldots 0.24$, з медіаною розподілу 0.049 , яка, як зазначалось вище, для повної вибірки CSFG становить 0.2 .

Частка теплового випромінювання галактик у радіоконтинуумі на 1.4 ГГи. За припущення, що електронна густина становить $100 \mathrm{~cm}^{-3}$, а густина Не+ - 8.1\% від густини протонів, типових для галактик вибірки, для кожної з відібраних 193 галактик потік теплового компонента в загальному монохроматичному випромінюванні у радіоконтинуумі на 1.4 ГГц на основі роботи [7] було визначено із такого співвідношення:

$$
\frac{F(1.4 \mathrm{GHz}, \text { thermal })}{F\left(H_{\beta}\right)}=0.347 \times 10^{10}\left(\frac{\Theta}{10^{4} \mathrm{~K}}\right)^{0.52},
$$

де $F(1.4 \mathrm{GHz}$, thermal) - це потік теплового компонента в загальному випромінюванні в радіоконтинуумі на 1.4 ГГц у Ян; $F\left(H_{\beta}\right)$ - потік в емісійній лінії $H_{\beta}$ у ерг $\mathrm{cm}^{-2} \mathrm{c}^{-1}$ та $\Theta$ - електронна температура у кельвінах, які визначено у роботі [43] з дослідження спектрального розподілу енергії окремих CSFG галактик. Частка теплового компонента у загальному монохроматичному випромінюванні в радіоконтинуумі визначалась як

$$
A=F(1.4 \mathrm{GHz} \text {, thermal }) / F(1.4 \mathrm{GHz}) \text {, }
$$

де $\mathrm{F}(1.4 \mathrm{GHz})$ - загальний потік випромінювання в радіоконтинуумі на 1.4 ГГц у Ян.

Перед аналізом результатів розглянемо точність отриманих оцінок. Потік в емісійній лінії Нß визначається досить точно. При розрахунках потоку теплового компонента в радіоконтинуумі потік $F(H \beta)$ було належним чином відкореговано за екстинкцію. Дослідниками також було детально обговорено проведення корекції [36]. Залишилося відкритим питання корекції за апертуру спостережень. Візуальний аналіз галактик вибірки показав, що вони досить компактні, але не точкові об'єкти. У вибірку увійшли галактики, які візуально є компактною яскравою ділянкою зореутворення, для якої з певною шириною щілини спектрографа отримано спектр, яка розміщена на тлі більшого за кутовими розмірами випромінювання у видимому діапазоні. Корекція за апертуру спостережень, яку проводять із порівняння видимих зоряних величин, отриманих за даними спостережень із певною апертурою та модельними розрахунками (ці дані подано в базі SDSS), базується на припущенні, що розподіл яскравості у щілині та по всій поверхні галактики однаковий. Для неточкових об'єктів, якими є галактики вибірки, це припущення некоректне. 3 огляду на це розрахунки частки теплового компонента в загальному монохроматичному випромінюванні в радіоконтинуумі було проведено у двох варіантах: 1) поправку за апертуру враховано, але ії̈ обмежено однією зоряною величиною; 2) без урахування апертури спостережень, що веде до недооцінювання величини $F(H \beta)$ потоку випромінювання у лінії $H \beta$, а відтак і частки теплового компонента. Ми будемо розглядати два варіанти опрацювання, а саме з поправками за поглинання та апертуру (обмежена однією зоряною величиною) та з поправками тільки за поглинання, як відповідно верхню та нижню межу оцінки частки теплового випромінювання для галактик вибірки.

Для потоку $F_{1.4 \mathrm{Gz}}$ випромінювання в радіоконтинуумі в каталогах наведено похибки вимірювання. Однак наскільки вони адекватні? Для відповіді на це запитання порівняємо потоки від об'єктів, що увійшли в наш перелік та мають потоки за даними обох каталогів радіоджерел (див. рис. 1). Відхилення даних від лінії рівності показує рівень похибок, який є вищим за похибки, наведені в каталогах. Потоки можуть відрізняться між собою в кілька разів, що показує: точність оцінки частки теплового випромінювання не перевищує $50 \%$. Частіше потік за даними NVSS перевищує потік за точнішими даними FIRST. Можливо, це пов'язано з тим, що чутливість FIRST зменшується при спостереженні об'єктів розмірами понад 10". FIRST у галактиках із розмірами 12" фріксує близько 84 \% випромінювання, і ця величина падає зі збільшенням розміру об'єкта [3]. Для розрахунків у всіх випадках, коли були дані про випромінювання за двома каталогами, ми використовували потоки, наведені в каталозі FIRST.

На рис. 2 (гістограма зі штрихуванням) наведено розподіл частки теплового випромінювання A, точніше log A., для випадку, коли враховано корекцію за апертуру. 3 гістограми видно, що розподіл добре відповідає лог-нормальному. Середнє значення А дорівнює $16.2 \%$, значення медіани розподілу $13.9 \%$, а $\exp (<\ln A>)=14.5 \%$, де $<\ln A>$ позначає усереднене значення логарифма А. Остання величина збігається із середнім геометричним оцінок частки теплового випромінювання в загальному випромінюванні в радіоконтинуумі на 1.4 ГГц для галактик вибірки. 3 розподілу отримано, що $A<12$ \% для 43 \% галактик вибірки, тоді як A >15 \% для 57 \% галактик CSFG вибірки з даними випромінювання в радіоконтинуумі в радіоконтинуумі на 1.4 ГГц. Для порівняння ми провели аналогічний аналіз для частки теплового випромінювання, розрахованої без корекції за апертуру спостережень. Розподіл, наведений на рис. 2 (контур без штрихування), також нагадує лог-нормальний, але його середні значення зменшуються. Середнє значення А дорівнює $7.3 \%$, медіана розподілу $6.02 \%$, а $\exp (<\ln A>)=5.9 \%$. Отримано, що у цьому випадку $87.6 \%$ галактик мають частку теплового випромінювання в радіоконтинуумі $A<12 \%$. Для нормальних галактик отримано оцінку $A \sim 11 \%$ [11]. $\mathrm{A} 3$ порівняння швидкостей зореутворення, визначених за випромінювання в радіоконтинуумі на 1.4 ГГц (дані NVSS) та далекому інфрачервоному діапазоні (дані IRAS) нижню межу величини А оцінено у 13 \% [25]. 


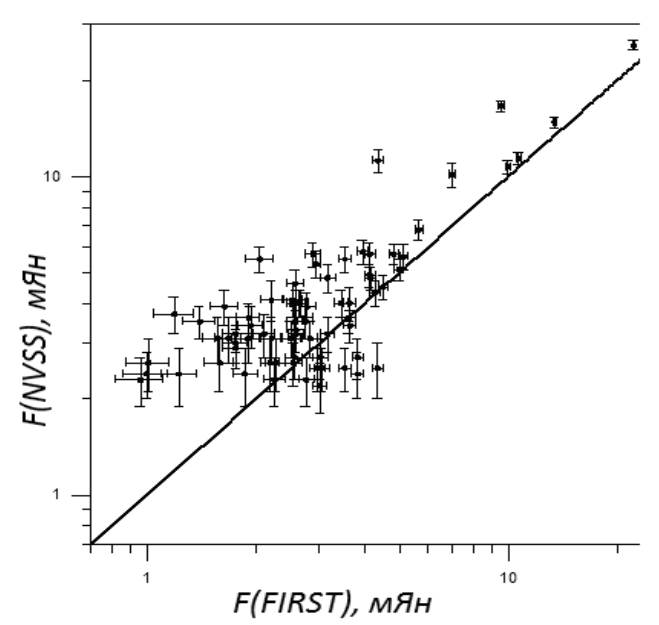

Рис. 1. Порівняння потоків випромінювання у радіоконтинуумі на частоті 1.4 ГГц за каталогами NVSS та FIRST. Пряма лінія відповідає їх рівності.

"Вуса" відповідають похибкам, наведеним у каталогах

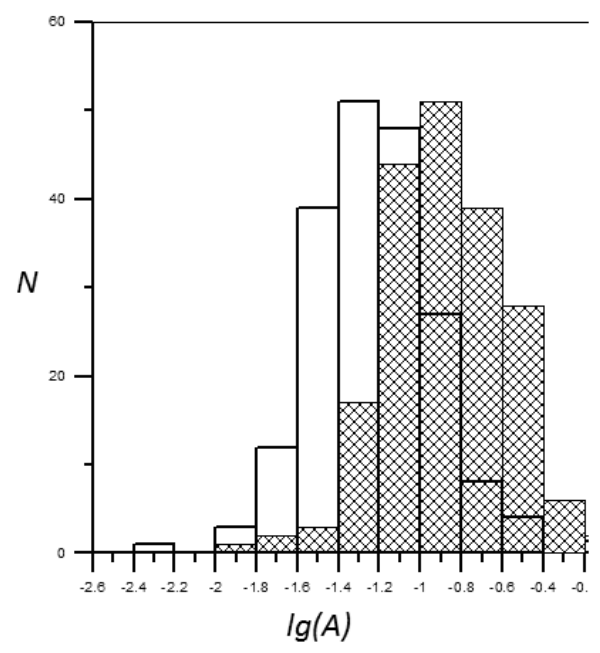

Рис. 2. Розподіл логарифма А частки теплового компонента у загальному випромінюванні у радіоконтинуумі на 1.4 ГГц. На гістограмах зі штрихуванням приведено результати, отримані з урахуванням корекції за апертуру спостережень, контуром - без корекції за апертуру

Для порівняння, як уже зазначалось вище [35, 38], проводили дослідження випромінювання у радіоконтинуумі на 1.4 ГГц 52-x LCG галактик - компактних галактик високої світності у лінії Нß, що свідчить про молодий спалах зореутворення. Значення червоного зміщення $z$ вибірки 52 галактик із радіоданими лежать у діапазоні від 0.015 до 0.223 медіаною вибірки 0.06, тобто є близьким до отриманих для 193 галактик вибірки CSFG. Для вибірки LCG галактик із даними про випромінювання в радіоконтинуумі було отримано, що частка теплового випромінювання в радіоконтинуумі лежить у межах від 2 до $47 \%$, з медіаною та середнім 14 та 17 \%, відповідно. Результати, отримані для 52-х LCG галактик та 193-х CSFG (з неповним урахуванням апертури), є близькими.

Ми провели статистичний аналіз залежності логарифма частки теплового випромінювання від деяких параметрів галактик, визначених у роботі [43]. Вибір саме IgА обумовлений лог-нормальним розподілом. Не було виявлено статистично значущої залежності від вмісту важких елементів й електронної температури t, визначених у роботі [43], натомість $€$ залежність від $E W\left(H_{\beta}\right)$ еквівалентної ширини емісійної лінії $H \beta$ та показника кольору $g-r$ (модельних значень зоряної величини у відповідних смугах з бази даних SDSS). На рис. 3, 4 показано, що $A$ зростає при збільшенні $E W\left(H_{\beta}\right)$. Оскільки $E W(H \beta)$ зменшується після спалаху зореутворення [31, 39, 42], то можна очікувати, що частка теплового ви-

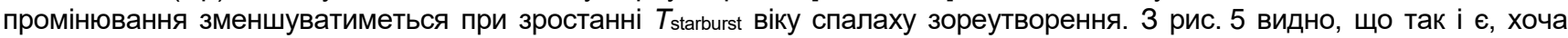
залежність менш виразна, ніж від $E W\left(H_{\beta}\right)$. Можливо, це пов'язано з тим, що вміст важких елементів у галактик вибірки різний, хоч і нижчий від сонячного, а зв'язок $E W\left(H_{\beta}\right)-T_{\text {starburst }} €$ чутливим до цього параметру $[31,39,42]$.

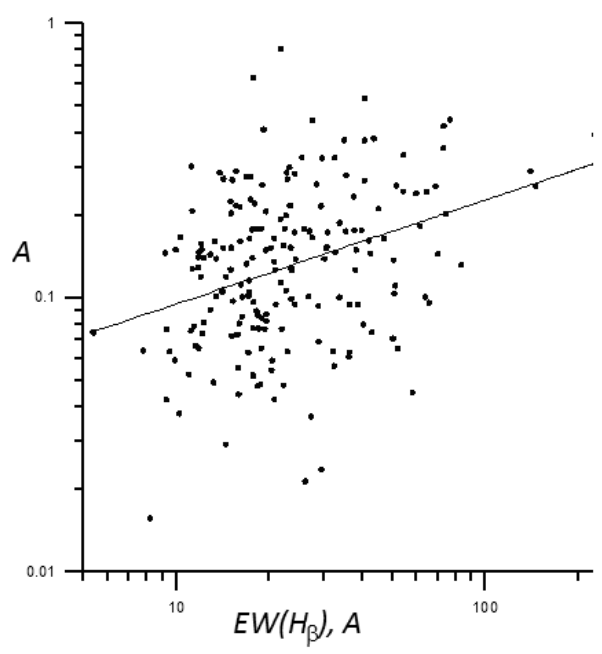

Рис. 3. Залежність $A$ частки теплового компонента у загальному випромінюванні в радіоконтинуумі на 1.4 ГГц від $E W\left(H_{\beta}\right)$ еквівалентної ширини емісійної лінії $H_{\beta}$ (враховано корекцію за апертуру). Пряма лінія - найкраща апроксимація залежності $\log A-\log \left(E W\left(H_{\beta}\right)\right)$, яку отримано методом найменших квадратів

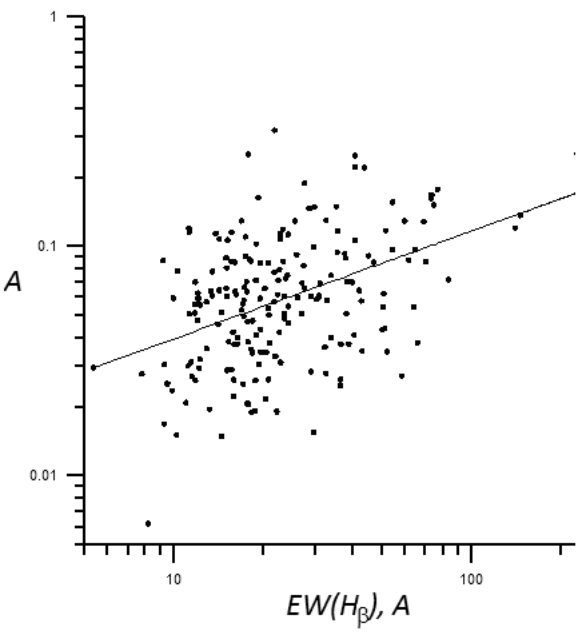

Рис. 4. Залежність $A$ частки теплового компонента у загальному випромінюванні в радіоконтинуумі на 1.4 ГГц від $E W\left(H_{\beta}\right)$ еквівалентної ширини емісійної лінії $H_{\beta}$ (без корекції за апертуру). Пряма лінія - найкраща апроксимація залежності $\log A-\log \left(E W\left(H_{\beta}\right)\right)$, яку отримано методом найменших квадратів

Аналіз залежності від індексу кольору натомість не може бути проведений так просто. Можна побудувати рис. 6 , з якого начебто випливає, що частка теплового випромінювання падає при його зростанні. Однак це неправильний висновок. Річ у тому, що залежність від $E W(H \beta)$ більш виразна, а $E W(H \beta)$ й індекс кольору змінюються зкорельовано 
для вибірки, що використовується. Коректним буде провести багаторегресійний аналіз, використавши метод найменших квадратів для визначення коефіцієнтів і тест Фішера [16] для визначення їхньої статистичної значущості. Ми розглядали простішу модель, а саме:

$$
\lg (A)=C_{1}+C_{2}\left(W-W_{0}\right)+C_{3}\left(I-I_{0}\right)
$$

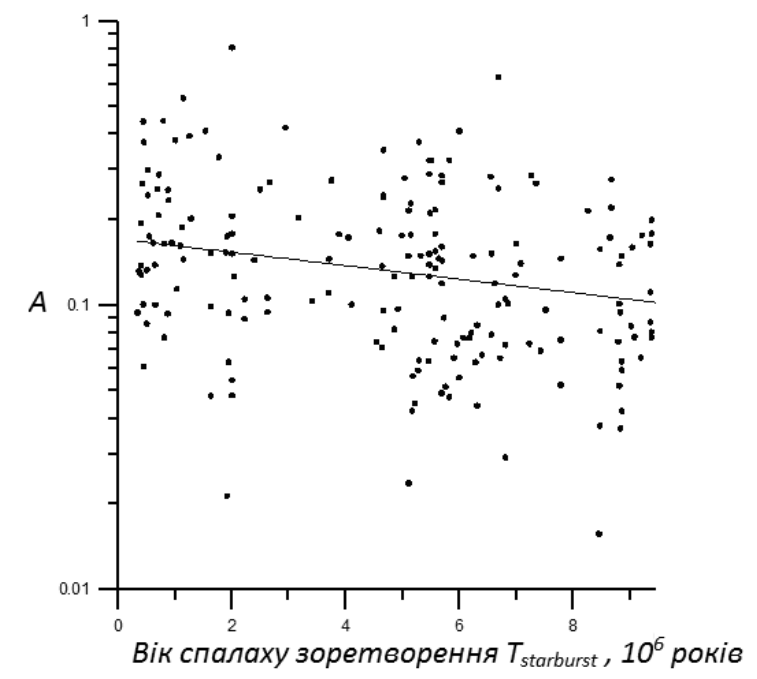

Рис. 5. Залежність А частки теплового компонента у загальному випромінюванні в радіоконтинуумі на 1.4 ГГц від віку спалаху зореутворення Tstarburst (ураховано корекцію за апертуру). Пряма лінія - найкраща апроксимація залежності logA-Tstarburst, яку отримано методом найменших квадратів

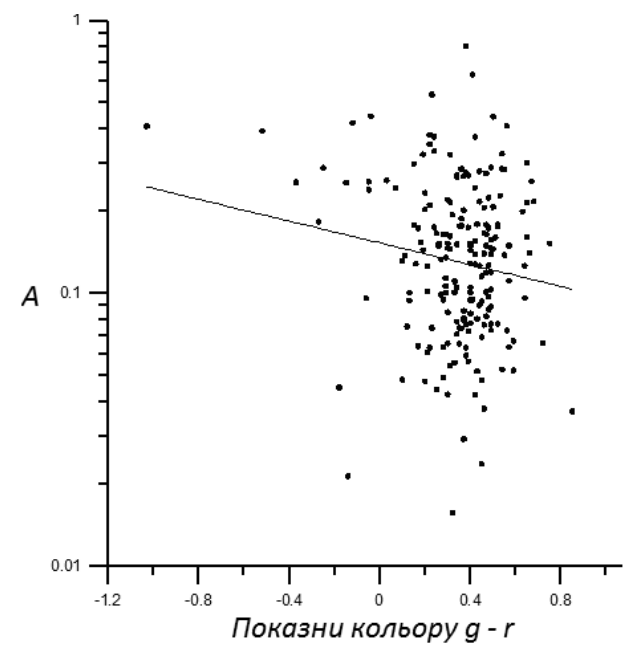

Рис. 6. Залежність $A$ частки теплового компонента у загальному випромінюванні в радіоконтинуумі на 1.4 ГГц від індексу кольору $g$ - $r$ (ураховано корекцію за апертуру). Пряма лінія - найкраща апроксимація залежності $\log A-(g-r)$, яку отримано методом найменших квадратів

Ми позначили $W$ еквівалентну ширину $E W(H \beta)$, скореговану за червоне зміщення, а I - індекс кольору. Величини з індексом 0 відповідають середнім значенням даних показників у вибірці, вони введені для того, щоб регресори у (3) були практично ортогональні [17]. Ми використовуємо $W_{0}=29.3$ та $I_{0}=0.342$. Для потоків, скорегованих за поглинання й апертуру, отримуємо $C_{1}=-0.884 \pm 0.02, C_{2}=0.0044 \pm 0.001, C_{3}=0.23 \pm 0.13$. Статистична значущість останнього доданка за критерієм Фішера характеризується величиною $F=3.1$, що відповідає ймовірності його значущості $92 \%$. Для другого доданка вона перевищує $99.9984 \%$. Для потоків, не скорегованих за апертуру, маємо $C_{1}=-1.22 \pm 0.02$, $C_{2}=0.0053 \pm 0.001, C_{3}=0.23 \pm 0.13$. Статистична значущість останнього доданка за критерієм Фішера характеризується величиною $F=3.5$, яка відповідає ймовірності його значущості 94 \%. Ми бачимо, що у двох варіантах опрацювання коефіцієнт перед останнім доданком $€$ додатним, тобто частка теплового випромінювання зростає зі зростанням індексу кольору.

Висновки. Ми отримали оцінки логарифма частки теплового випромінювання 193 компактних галактик з активним зореутворенням із вибірки CSFG у випромінюванні в радіоконтинуумі на частоті 1.4 ГГц. Як нижня так і верхня межа має лог-нормальні розподіли із середніми значеннями, що відповідають часткам у 5,9 та 14,5\%, відповідно. Частка зростає за збільшення еквівалентної ширини емісійної лінії $H_{\beta}$ за постійного показника кольору, або за збільшення показника кольору за постійнньої еквівалентної ширини емісійної лінії $H_{\beta}$. Залежність від обох параметрів має вигляд (3) з параметрами та похибками, наведеними у статті. За збільшення віку спалаху зореутворення другий доданок, пов'язаний із $E W\left(H_{\beta}\right)$ еквівалентною шириною емісійної лінії $H_{\beta}$, зменшується, а третій доданок, пов'язаний із показником кольору $g-r$, збільшується, але вплив другого доданку превалює, що відповідає загальному зменшенню частки теплового випромінювання (див. рис. 6).

Під час виконання роботи було використано інформацію з бази даних позагалактичних джерел NED (NASA/IPAC Extragalactic Database), що функціонує під керівництвом Jet Propulsion Laboratory, California Institute of Technology, при контракті з National Aeronautics and Space Administration; огляди Sloan Digital Sky Survey (SDSS) та SDSS-II, які виконано та функціонують завдяки Alfred P. Sloan Foundation, the Participating Institutions, the National Science Foundation, the U.S. Department of Energy, the National Aeronautics and Space Administration, the Japanese Monbukagakusho, the Max Planck Society та the Higher Education Funding Council for England; огляди NVSS (National Radio Astronomy Observatory Very Large Array Sky Survey) та FIRST.

Список використаних джерел

1. A comparison of independent star formation diagnostics for an ultraviolet-selected sample of nearby galaxies / M. Sullivan, B. Mobasher, B. Chan et al. // Astrophys. J. - 2001. - V. 558. - P. 72-80.

2. Baldwin J.A. Classification parameters for the emission line spectra of extragalactic objectsn / J.A. Baldwin, M.M. Phillips, R. Terlevich // PASP. - 1981. - V. 93, № 551. - P. 5-19.

3. Becker R.H. The FIRST Survey: Faint Images of the Radio Sky at Twenty Centimeters / R.H. Becker, R.L. White, D.J. Helfand // Astrophys. J. - 1995. - V. 450. - P. 559.

4. Bell E.F. Estimating star formation rates from infrared and radio luminosities: the origin of the radio-infrared correlation/ E.F. Bell // Astrophys. J. - 2003. - V. 586, № 2. - P. 794-813. 
5. Bicay M.D. The 60 micron to 20 centimeter infrared-to-radio ratio within spiral galaxies/ M.D. Bicay, G. Helou // Astrophys. J. - 1990 . - Vol. 362 . - P. 59-73.

6. Calzetti D. Star Formation Rate Indicators / D. Calzetti // Secular Evolution of Galaxies, by Jesús Falcón-Barroso, and Johan H. Knapen. - Cambridge, 2013.

7. Caplan J. Extinction and reddening of HII regions in the Large Magellanic Cloud / J. Caplan, L. Deharveng // Astron. Astrophys. - 1986. - V. 155. - P. 297-313.

8. Colgate S.A. The supernova envelope shock origin of cosmic rays / S.A. Colgate // Advances in Space Research. - 1984. - Vol. 4, issue 2-3. - P. 367-379.

9. Comparison of Ha and UV Star Formation Rates in the Local Volume: Systematic Discrepancies for Dwarf Galaxies / J.C. Lee, A. Gil de Paz, C. Tremonti et al. // Astrophys. J. - 2009. - Vol. 706, issue 1. - P. 599-613.

10. Condon J.J. Correlation between far-infrared, radio and blue luminosities of spiral galaxies / J.J. Condon, M.L. Anderson, G. Helou // Astrophys. J. - 1991. - V. 376. - P. 95-103.

11. Condon J.J. Radio emission from normal galaxies / J.J. Condon // Ann. Rev. Astron. Astrophys. - 1992. - V. 30. - P. 575-611

12. Continuous Mid-Infrared Star Formation Rate Indicators: Diagnostics for $0<z<3$ Star-Forming Galaxies / A.J. Battisti, D. Calzetti, B.D. Johnson, D. Elbaz // Astrophys. J. - 2015. - Vol. 800, issue 2. - Id. 143.

13. Dust emission in star-forming dwarf galaxies: general properties and the nature of sub-mm excess / I.Y. Izotov, N.G. Guseva, K.J. Fricke et al. // Astron. Astrophys. - 2014. - Vol. 570. - Id. A97.

14. Dust-corrected Star Formation Rates of Galaxies. I. Combinations of Ha and Infrared Tracers / R.C., Jr. Kennicutt, C.-N. Hao, D. Calzetti et al. // Astrophys. J. - 2009. - Vol. 703, issue 2. - P. 1672-1695.

15. Dust-corrected Star Formation Rates of Galaxies. II. Combinations of Ultraviolet and Infrared Tracers / C.-N. Hao, R.C. Kennicutt, B.D. Johnson et al. // Astrophys. J. - 2011. - Vol. 741, issue 2. - Id. 124.

16. Fisher R.A. Statistical methods for research workers / R.A. Fisher. - L., 1950

17. Forsythe G. Generation and Use of Orthogonal Polynomials for Data-Fitting with a Digital Computer / G. Forsythe // Journal of the Society for Industrial and Applied Mathematics. - 1957. - № 5 (2). - P. 74-88.

18. GALEX-SDSS-WISE Legacy Catalog (GSWLC): Star Formation Rates, Stellar Masses, and Dust Attenuations of 700,000 Low-redshift Galaxies / S. Salim, J.C. Lee, S. Janowiecki et al. // Astrophys. J. Suppl. Ser. - 2016. - Vol. 227, iss.1. - Art. id. 2.

19. Hirashita $H$. Dust-to-gas ratio and star formation history of blue compact dwarf galaxies / H. Hirashita, Y.Y. Tajiri, H. Kamaya // Astron. and Astrophys. - 2002. - V. 388. - P. 439-445.

20. Hopkins A.M. On the evolution of star forming galaxies / A.M. Hopkins // Astrophys. J. - 2004. - V. 615,№ 1. - P. $209-221$.

21. Hopkins A.M. Star formation rates of local blue compact dwarf galaxies. I. $1.4 \mathrm{GHz}$ and 60 micron luminosities / A.M. Hopkins, R.E. Schulte-Labreck, I.O. Drozdovsky // Astron. J. - 2002. - V. 124, № 2. - P. 862-876.

22. Hunter D.A. Star formation properties of a large sample of irregular galaxies / D.A. Hunter, B.G. Elmegreen // Astron. J. - 2004. - V. 128, № 5. - P. 2170-2205.

23. Izotova I. Star formation rate in starburst galaxies / I. Izotova, S.L. Parnovsky, Yu. Izotov // New Astronomy Reviews. - 2000. - V. 44. - P. 283-285.

24. Izotova I.Y. Emission-line galaxies from SDSS DR4: Statistical studies of the current star formation / I.Y. Izotova, S.L. Parnovsky (in ukr.: Изотова И.Ю. Эмиссионные галактики из SDSS DR4 обзора: стат. исслед. текущего звездообразования / И.Ю. Изотова, С.Л. Парновский // Кinematics аnd Physics of Celestial Bodies. - 2008. - Vol. 24, issue 4. - P. 183-191.

25. Izotova I.Y. Isolated galaxies: far infrared properties, current star formation rates and efficiency / I.Y. Izotova, S.L. Parnovsky, A.A. Tyutyunnyk (in ukr.: Ізотова И.Ю. Изолированные галактики: излучение в дальнем инфракрасном диапазоне, скорость и эффективность текущего звездообразования / И.Ю. Изотова, С.Л. Парновский, А.А. Тютюнник // Kinematika i Fizika Nebesnykh Tel. - 2006. - Т. 22, № 3. - С. $187-203$.

26. Izotova I.Y. Star formation rate in star-forming galaxies / I.Y. Izotova, Y.I. Izotov // Astrophysics and Space Science. - 2018. - Vol. 363, issue 3. - Id. 47.

27. Kennicutt $R$. The origin of the nonthetmal radio emission in normal disk galaxies / R. Kennicutt // Astron. Astrophys. - 1983. - Vol. $120 .-$ P. 219.

28. Kennicutt R.C.Jr. Star formation in galaxies along the Hubble sequence / R.C. Kennicutt Jr. // Ann. Rev. Astron. Astrophys. - 1998. - V. 36. - P. 189-231.

29. Kimball A.E. A unified Catalog of Radio Objects Detected by NVSS, FIRST, WENSS, GB6 and SDSS / A.E. Kimball, Ž. Ivezić // Astron. J. - 2008. - Vol. 136, issue 2. - P. 684-712.

30. Lee J.C. The Calibration of Star Formation Rate Indicators for WISE $22 \mu \mathrm{m}-$ Selected Galaxies in the Sloan Digital Sky Survey / J.C. Lee, H.S. Hwang, J. Ko // Astrophys. J. - 2013. - Vol. 774, issue 1. - Id. 62

31. Leitherer C. Starburst99: Synthesis Models for Galaxies with Active Star Formation / C. Leitherer, D. Schaerer, J.D. Goldader et al. // Astrophys. J. Suppl. Ser. - 1999. - Vol. 123, issue 1. - P. 3-40.

32. Multiwavelength star formations indicators: observations / H.R. Schmitt, D. Calzetti., L. Armus et al. // Astrophys. J. Suppl. Ser. - 2006 . - V. 164 , № 1. - P. 52-80

33. Multi-wavelength study of 14 star-forming galaxies from the Sloan Digital Sky survey / I.Y. Izotov, N.G. Guseva, K.J. Fricke, C. Henkel // Astron. Astrophys. - 2014. - Vol. 561. - Id. A33.

34. Parnovsky S.L. A technique for estimation of starburst masses and ages in luminous compact galaxies / S.L. Parnovsky, I.Yu. Izotova // Astrophysics and Space Science. - 2013. - V. 348. - P. 199-209.

35. Parnovsky S.L. Emission of Compact Starburst Galaxies in Radio Continuum at $1.4 \mathrm{GHz} /$ S.L. Parnovsky, I.Y. Izotova (in ukr.: Парновський C.Л. Teплове випромінювання компактних емісійних галактик у радіоконтинуумі на частоті 1.4 ГГц / С.Л. Парновський, І.Ю. Ізотова // Bull. Куіv National Тагаs Shevchenko University. Astronomy. - 2014. - Вип. 51. - С. 18-22.

36. Parnovsky S.L. Ha and UV luminosities and star formation rates of large sample of luminous compact galaxies / S.L. Parnovsky, I.Yu. Izotova, Y.I. Izotov // Astrophysics and Space Science. - 2013. - № 343. - P. 361-376.

37. Parnovsky S.L. Luminosity function of luminous compact star-forming galaxies / S.L. Parnovsky, I.Yu. Izotova // Astrophysics and Space Science.

-2016. - V. 361.- Issue 3. - Id. 111.

38. Parnovsky S.L. Radio emission at $1.4 \mathrm{GHz}$ from luminous compact galaxies / S.L. Parnovsky, I.Y. Izotova // Astronomische Nachrichten / Astronomical Notes. - 2015. - V. 336, № 3. - P. 276-283.

39. Schaerer D. New models for Wolf-Rayet and O star population in young starburst / D. Schaerer, W.D. Vacca // Astrophys. J. - $1998 .-$ V. 497, № 2. - P. 618-644.

40. Star formation in the nearby universe: the ultraviolet and infrared points of view / J. Iglesias-Paramo, V. Buat, T.T. et al. // Astrophys. J. Suppl. Ser. - 2006. - V. 164, № 1. - P. 38-51.

41. Star formation rate indicators in the Sloan Digital Sky Survey / A.M. Hopkins, C.J. Miller, R.C. Nichol et al. // Astrophys. J. - 2003. - V. 599. - P. 971-991.

42. Stasinska G. HII galaxies versus photoionisation models for evolving starbursts / G. Stasinska, C. Leitherer // Astrophys. J. Suppl. - 1996. - V. 107, № 2. - P. 661-692.

43. The bursting nature of star formation in compact star-forming galaxies from the Sloan Digital Sky Survey / I.Y. Izotov, N.G. Guseva, K.J. Fricke,

C. Henkel // Mon. Not. R. Astron. Soc. - 2016. - Vol. 462, issue 4.- P. 4427-4434.

44. The Calibration of Monochromatic Far-Infrared Star Formation Rate Indicators / D. Calzetti, S.-Y. Wu, S. Hong et al. // Astrophys. J. - 2010. - Vol. 714, issue 2. - P. 1256-1279.

45. The effect of star formation on the far-infrared-radio correlation within galaxies / E.J. Murphy, G. Helou, R. Braun et al. // Astrophys. J. - 2006. - Vol. 651, issue 2. - P. L111-L115.

46. The Eleventh and Twelfth Data Releases of the Sloan Digital Sky Survey: Final Data from SDSS-III / S. Alam, F.D. Albareti, P. Allende et al. // Astrophys. J. Suppl. Ser. - 2015. - V. 219, issue 1. - Id. 12.

47. The NRAO VLA sky survey / J.J. Condon, W.D. Cotton, E.W. Greisen et al. // Astron. J. - 1998. - V. 115, № 5. - P. 1693-1716.

48. Towards universal hybrid star formation rate estimators / M. Boquien, R. Kennicutt, D. Calzetti et al. // Astron. Astrophys. - 2016. - Vol. 591. - Id. A6. 
S. Parnovsky, Dr. Sci., Prof.

I. Izotova, Ph. D.

Astronomical Observatory of Taras Shevchenko National University of Kyiv, Kyiv

\section{COMPACT STAR-FORMING GALAXIES: THE FRACTION OF THERMAL EMISSION} IN THE RADIO CONTINUUM AT $1.4 \mathrm{GHZ}$

The fraction of thermal (free-free) emission in the radio continuum at the frequency of $1.4 \mathrm{GHz}$ is derived in 193 compact star-forming galaxies (CSFG). These galaxies with detected radio emission represent the subsample of a larger CSFG sample of about 14000 galaxies (Izotov, Y.I., Guseva, N.G., Fricke, K.J., Henkel, C.: Mon. Not. R. Astron. Soc. 2016, 462, 4427) selected from the Data Release 12 of the Sloan Digital Sky Survey (SDSS) (Alam, S., et al.: Astrophys. J. Suppl. Ser. 219, 12, 2015). We use the $1.4 \mathrm{GHz}$ fluxes from the FIRST (Becker R.H., White R.L., \& Helfand D.J.: 1995, ApJ, 450, 559) and NVSS (Condon, J.J., Cotton, W.D., Greisen, E.W., et al.: 1998, AJ, 115, 1693) catalogues. The fluxes of the thermal component at $1.4 \mathrm{GHz}$ are derived from the extinction- and aperture-corrected fluxes of the Hß emission line in the SDSS spectra following to (Caplan, J., \& Deharveng, L.: 1986, A\&A, 155, 297) and are compared with the total fluxes in radio continuum.

The distribution of the fraction of thermal emission $A$ at $1.4 \mathrm{GHz}$ is similar to the log-normal one. Its median values of $6 \%$ and $14 \%$ are derived respectively with the $H_{\beta}$ emission line fluxes which are non-corrected and corrected for aperture. We consider these values as lower and upper limits and discuss their uncertainties introduced by aperture corrections. The derived fractions of thermal emission are similar to those found previously for different types of star-forming galaxies.

We study the dependence of $A$ on various parameters and find strong correlation with the equivalent width of the $H \beta$ emission line $W$ and the $g$ $r$ colour index $I$. The $A$ value increases with increasing of the equivalent width $W$ at a fixed colour index $I$ or with increasing of the colour index $I$ at a fixed equivalent width $W$. In the general case, when both $W$ and $I$ are varied, we obtain the relation $\log (A)=C_{1}+C_{2}\left(W-W_{0}\right)+C_{3}\left(I-I_{0}\right)$ where $W_{0}=29.3$, $I_{0}=0.342, C_{1}=-0.884 \pm 0.02, C_{2}=0.0044 \pm 0.001$ and $C_{3}=0.23 \pm 0.13$. Additionally, we find that the fraction of thermal emission at $1.4 \mathrm{GHz}$ is lower for older starbursts.

Key words: star-forming galaxies, continuum radio emission, thermal emission.

С. Парновский, д-р физ.-мат. наук, проф.,

И. Изотова, канд. физ.-мат. наук

Киевский национальный университет имени Тараса Шевченко

\section{КОМПАКТНЫЕ ГАЛАКТИКИ С АКТИВНЫМ ЗВЕЗДООБРАЗОВАНИЕМ: ТЕПЛОВОЕ ИЗЛУЧЕНИЕ В РАДИОКОНТИНУУМЕ НА ЧАСТОТЕ 1.4 ГГЦ}

Была определена часть теплового компонента в полном излучении в радиоконтинууме на частоте 1.4 ГГц от 193 компактных галактик с активным звездообразованием. Распределение этой величины близко к лог-нормальному с медианой между 6 \% и 14 \%. Часть возрастает с увеличением $E W\left(H_{\beta}\right)$ эквивалентной ширини эмиссионной линии $H_{\beta}$ при постояннном индексе цвета g-r, или увеличении индекса цвета g-r при постоянной $E W\left(H_{\beta}\right)$ эквивалентной ширине эмиссионной линии $H_{\beta}$. Найдена зависимость от обоих параметров одновременно. При увеличении возраста вспышки звездообразования часть теплового излучения уменьшается. Не обнаружено статистически значимой зависимсти от обилия тяжелых элементов.

Ключевые слова: галактики с активным звездообразованием, излучение в радиоконтинууме, тепловое излучение.

удк 523.985

В. Лозицький, д-р фіз.-мат. наук Астрономічна обсерваторія Київського національного університету імені Тараса Шевченка, Київ

\section{ВИМІРЮВАННЯ ЛОКАЛЬНИХ МАГНІТНИХ ПОЛІВ У СОНЯЧНОГО СПАЛАХУ ЗА РОЗЩЕПЛЕННЯМ ЕМІСІЙНИХ ПІКІВ У ЯДРАХ СПЕКТРАЛЬНИХ ЛІНІЙ}

Досліджено сонячний спалах 19.07.2000 р. балу M 5.6 / теріал отримано на ешельному спектрографі горизонтального сонячного телескопа Астрономічної обсерваторії Київського національного університету імені Тараса Шевченка. Локальні магнітні поля у цьому спалаху вимірювали за

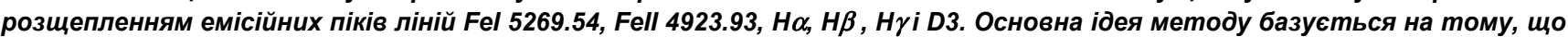
спалахова емісія в деяких спектральних лініях чітко розділяється на дві компоненти: (1) більш широку і неполяризовану і (2) вужчу і поляризовану, зі значним зеєманівським розщепленням. Це вказує на двокомпонентну структуру маенітного поля, із суттєво різними магнітними полями і термодинамічними умовами у двох компонентах. Завдяки тому, що поляризована емісія досить упевнено відділяється від неполяризованої, можна виміряти локальні магнітні поля безпосередньо у другій (сильній) компоненті, притому незалежно від фактора заповнення. Було з'ясовано, що у яскравому вузлі цього спалаху, який проектувався на півтінь сонячної плями, ефективне магнітне поле $B_{\text {eff }}$ л лініях Fel 6301.5 i 6302.5, виміряне по розщепленню фраунгофрерових профілів, дорівнювало 900 Гс. Однак розщеплення емісійних піків у лініях $H_{\alpha}, H_{\beta}, H_{\gamma}$ i D3 відповідає 1000 Гc, 1400 Гc, 1450 Гс $i \approx 0$ відповідно, за величини похибок 30-50 Гс для зазначених ліній Fel i близько 100-150 Гс для інших ліній. Така розбіжність результатів імовірно пов'язана з тим, що у випадку ліній Fel 6301.5 i 6302.5 величина $B_{\text {eff }}$ відображає кілька параметрів, у тому числі величину фонового поля, фрактор заповнення і напруженість локальних полів у сильній компоненті. На противагу цьому, дані по лініях $H_{\alpha}, H_{\beta}, H_{\gamma} i D 3$ відображають переважно локальні поля в сильній компоненті і вказують на немонотонний розподіл магнітного поля 3 висотою, з його максимумом на хромосфрерному рівні сонячного спалаху. Раніше в цьому спаласі, при побудові його напівемпіричної моделі, було виявлено локальне підсилення магнітного поля на фотосферному рівні, причому його величина досягала 1500 Гс. Ці дані підтверджуються прямими вимірюваннями розщеплення емісійних піків у лініях Fel 5269.54 i Fell 4923.93, зәідно з якими магнітне поле у спалаху було $1250 \pm 100$ Гс. Таким чином, у зазначеному спалаху існувало принаймні дві ділянки (можливо, два плоских шари) локального підсилення магнітного поля.

Ключові слова: Сонце, сонячні магнітні поля, сонячні спалахи, ешельні зеєман-спектрограми, розщеплення емісійних піків, локальні напруженості магнітного поля у фотосфері і хромосфері. 